\title{
Characterization by Raman scattering, x-ray diffraction, and transmission electron microscopy of (AIAs)m(InAs)m short period superlattices grown by migration enhanced epitaxy
}

Bradshaw, J.; Song, X.J.; Shealy, J.R.; Zhu, J. G.; Østergaard, H.

Published in:

Journal of Applied Physics

Link to article, DOI:

10.1063/1.352139

Publication date:

1992

Document Version

Publisher's PDF, also known as Version of record

Link back to DTU Orbit

Citation (APA):

Bradshaw, J., Song, X. J., Shealy, J. R., Zhu, J. G., \& Østergaard, H. (1992). Characterization by Raman scattering, x-ray diffraction, and transmission electron microscopy of (AIAs)m(InAs)m short period superlattices grown by migration enhanced epitaxy. Journal of Applied Physics, 72(1), 308-310.

https://doi.org/10.1063/1.352139

\section{General rights}

Copyright and moral rights for the publications made accessible in the public portal are retained by the authors and/or other copyright owners and it is a condition of accessing publications that users recognise and abide by the legal requirements associated with these rights.

- Users may download and print one copy of any publication from the public portal for the purpose of private study or research.

- You may not further distribute the material or use it for any profit-making activity or commercial gain

- You may freely distribute the URL identifying the publication in the public portal 


\title{
Characterization by Raman scattering, $x$-ray diffraction, and transmission electron microscopy of (AlAs) ${ }_{m}($ InAs) $m$ short period superlattices grown by migration enhanced epitaxy
}

\author{
J. Bradshaw, ${ }^{\text {a) }}$ X. J. Song, ${ }^{\text {b) }}$ and J. R. Shealy \\ School of Electrical Engineering, Phillips Hall, Cornell University, Ithaca, New York 14853-5401 \\ J. G. Zhu ${ }^{\text {) }}$ \\ Department of Materials Science and Engineering, Bard Hall, Cornell University, Ithaca, \\ New York 14853-1501 \\ H. Фstergaard \\ Laboratory for Semiconductor Technology, Electronics Institute, Technical University of Denmark, \\ Building 34A,DK-2800, Lyngby, Denmark
}

(Received 10 December 1991; accepted for publication 18 March 1992)

\begin{abstract}
We report growth of (InAs) ${ }_{1}(\mathrm{AlAs})_{i}$ and (InAs) ${ }_{2}(\mathrm{AlAs})_{2}$ strained layer superlattices by migration enhanced epitaxy. The samples were grown on InP (001) substrates and characterized by Raman spectroscopy, x-ray diffraction, and transmission electron microscopy. Satellite peaks in the $x$-ray data confirm the intended periodicity and indicate the presence of some disorder in the monolayer sample. The energies of the zone folded and quantum confined optic phonons are in reasonable agreement with calculations based on one-dimensional elastic continuum and linear chain models.
\end{abstract}

Short period superlattices (SPS) could potentially find application as replacements for the corresponding alloy in several III-V materials systems because the ordered structure is expected to reduce charge scattering and exciton broadening, due, respectively, to alloy potential fluctuations and clustering caused by immiscibility. ${ }^{1,2}$ $\mathrm{In}_{0.53} \mathrm{Ga}_{0.47} \mathrm{As}$ and $\mathrm{In}_{0.52} \mathrm{Al}_{0.48} \mathrm{As}$ lattice matched to $\mathrm{InP}$ have shown promise in modulation doped field effect transistors and high speed optical modulators because these materials exhibit high electron mobility, large band-edge discontinuity and large $\Gamma-X$ valley separation. ${ }^{3-6}$ Although the lattice mismatch between the binary compounds in both systems complicates epitaxial growth, several groups have successfully grown highly ordered (InAs) ${ }_{m}(\mathrm{GaAs})_{n}$ strained layer superlattices by molecular beam epitaxy (MBE) or organometallic vapor phase epitaxy (OMVPE) ${ }^{7-10}$ The InAs/AlAs system, on the other hand, has received considerably less attention. To date, there has been at least one report of MBE growth of this structure, ${ }^{11}$ but we believe this is the first report of $(\operatorname{InAs})_{m}(\mathrm{AlAs})_{m}$ grown by migration enhanced epitaxy (MEE).

Alternate deposition of metal atoms and $\mathrm{As}_{4}$ molecules at reduced temperatures $\left(200-500^{\circ} \mathrm{C}\right)$ results in layers with superior uniformity and interface abruptness. ${ }^{12}$ Under these conditions, surface migration of both group III and group V species is increased, and three-dimensional island growth is suppressed. Since MEE results in monolayer by monolayer growth, it is ideal for epitaxy of SPS structures. Recently it has been used to fabricate strained layer

\footnotetext{
a) Current address: Photonics Research Laboratory, Dept. of Chemistry, SUNY at Buffalo, Buffalo, NY 14214.

b) Current address: MBE Operations, Northeast Semiconductor, c/o ITT Technology Center, 7670 Enon Drive, Roanoke, VA 24019.

"Current address: National Renewable Energy Laboratory, 1617 Cole Blvd., Golden, CO 80401.
}

(InAs) ${ }_{m}(\mathrm{GaAs})_{n}$ layers with improved structural and optical characteristics. ${ }^{10}$ Here we describe the application of MEE to growth of mono- and bilayer superlattices in the InAs/AlAs system. Because of the relatively high activation energy of $\mathrm{Al}(\approx 1.6 \mathrm{eV})$, in conventional MBE it is desirable to grow $\mathrm{Al}$ containing compounds at elevated temperatures $\left(680-720^{\circ} \mathrm{C}\right)$ in order to allow surface migration. Growth of InAs, on the other hand, requires substrate temperatures lower than $500^{\circ} \mathrm{C}$ to prevent In desorption. Since MEE allows enhanced surface migration of all group III species at low temperature, it would seem to be well suited for this system.

(InAs) ${ }_{1}$ (AlAs) ${ }_{1}$ and (InAs) ${ }_{2}$ (AlAs) $)_{2}$ were grown on InP (001) substrates by MEE at $400^{\circ} \mathrm{C}$ in a computer controlled Varian Gen II. Prior to growth, the native oxide was removed by thermal desorption at $500^{\circ} \mathrm{C}$. After deposition of a $2000 \AA \AA \mathrm{In}_{0.52} \mathrm{Al} \mathrm{l}_{0.48} \mathrm{As}$ buffer layer, 100 periods of (InAs) ${ }_{1}(\mathrm{AlAs})_{1}$ or 50 periods of (InAs) ${ }_{2}(\mathrm{AlAs})_{2}$ were grown, giving a total superlattice thickness of $600 \AA$ in each case. This is below the critical thickness of $920 \AA$ for $\mathrm{In}_{0.50} \mathrm{AI}_{0.50} \mathrm{As}$, the average SPS composition, which is lattice mismatched to InP by $0.16 \% .^{13}$ Finally, a $500 \AA$ $\mathrm{In}_{0.52} \mathrm{Al}_{0.48} \mathrm{As}$ cap layer was grown. The group III beam fluxes were $3 \times 10^{14}$ atoms $/ \mathrm{cm}^{2} \mathrm{~s}$, corresponding to a growth rate of 0.5 monolayer $/ \mathrm{s}$. A clear streak reflection high energy electron diffraction (RHEED) pattern which alternated between $2 \times 4$ (As stabilized surface) and $4 \times 2$ (metal stabilized surface) persisted without attenuation, indicating that uniform two-dimensional growth was maintained. ${ }^{14}$

Raman spectroscopy has developed into a powerful characterization technique for compound semiconductor materials and heterostructures. In particular, superlattices display quantum confined optical and zone folded acoustic phonons which are highly sensitive to layer thickness and 


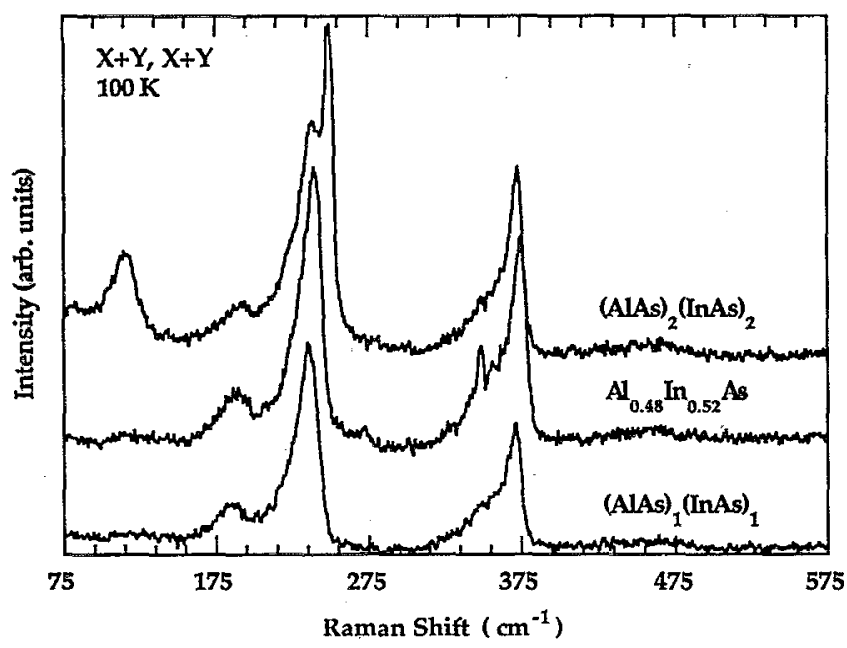

FIG. 1. Polarized Raman spectra of (InAs) ${ }_{2}(\mathrm{AlAs})_{2}$, (InAs) ${ }_{1}$ (AlAs) ${ }_{1}$, and $\mathrm{Al}_{0.48} \mathrm{In}_{0.52} \mathrm{As}$ alloy.

interface quality. ${ }^{15,16}$ Raman spectra were taken in backscattering geometry from the (001) crystal face using the 488 or $476 \mathrm{~nm}$ line of an $\mathrm{Ar}^{+}$laser. Figure 1 shows $z(x$ $+y, x+y) \vec{z}$ spectra of both samples as well as that of an $\mathrm{Al}_{0.48} \mathrm{In}_{0.52} \mathrm{As}$ alloy sample. The spectrum of the bilayer exhibits a peak at $115 \mathrm{~cm}^{-1}$ that is absent for the other two samples. Polarization measurements and phonon dispersion calculations based on a one-dimensional elastic continuum (Rytov) model ${ }^{15}$ lead us to assign this peak to the first zone folded acoustic doublet (unresolved in the experiment). The bulk values for the density and speed of sound of AlAs and InAs used in the calculation were uncorrected for strain. In structures that exhibit alternating biaxial compression and tension, this may not be a bad approximation since the average sound velocity is relatively insensitive to strain. In GaSb/AlSb superlattices, discrepancies between experimental data and the Rytov model (uncorrected for strain) have been attributed to the nonlinearity of the bulk dispersion only. ${ }^{17}$ Values for the density and sound velocity of InAs (AlAs) used in our calculation were $5.667(3.7285) \mathrm{g} / \mathrm{cm}^{3}$ and $3.834(5.118) \times 10^{5} \mathrm{~cm} / \mathrm{s}$. These parameters give a value for the first zone folded mode that is approximately $10 \mathrm{~cm}^{-1}$ higher than the observed peak. Adjustment of the layer thicknesses by integral monolayers does not give better agreement with experiment. As discussed in Ref. 17, the nonlinearity of the bulk dispersion would account for observation of the folded mode at a lower energy than that predicted by a model which assumes a constant average sound velocity. All three scans show a peak near $190 \mathrm{~cm}^{-1}$. For the alloy and bilayer samples this corresponds to a disorder activated LA mode and indicates some imperfection in the superlattice. The size of this peak relative to the optical mode is somewhat smaller in the superlattice sample than the alloy, indicating the improved ordering. On the other hand, a monolayer superlattice is expected to show a single folded mode at the energy of the bulk zone edge. In the monolayer scan this peak may thus be a zone folded acoustic phonon rather than a disorder related feature. The op-

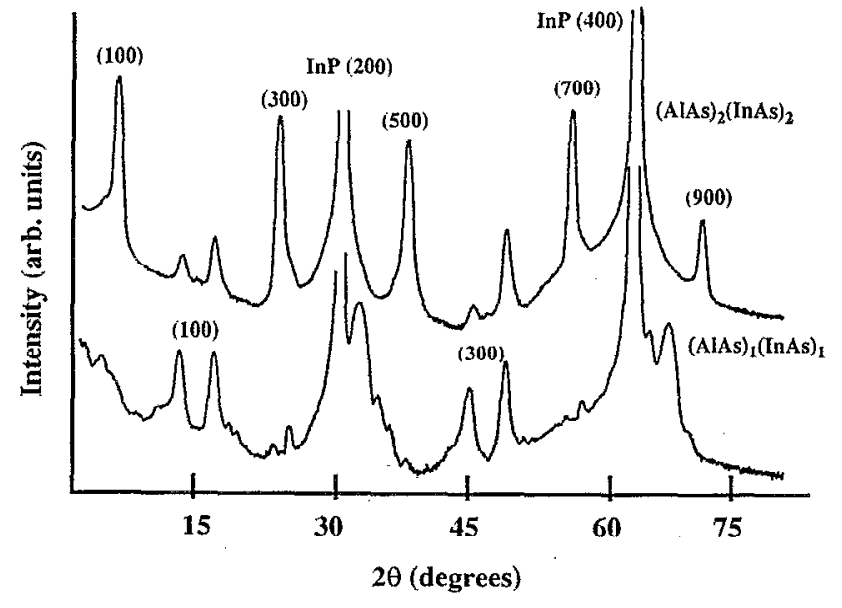

FIG. 2. X-ray diffraction scan of mono- and bilayer samples.

tical region of the spectrum in all cases shows peaks arising from the vibrations of AlAs $\left(\approx 360 \mathrm{~cm}^{-1}\right)$ and InAs $\left(\approx 230-250 \mathrm{~cm}^{-1}\right)$ atomic pairs. The peak near 350 $\mathrm{cm}^{-1}$ in the alloy is due to the LO phonon of the InP substrate. The spectrum of the bilayer sample shows two peaks in the InAs vibration energy range, the one at 238 $\mathrm{cm}^{-1}$ coming from the $\mathrm{Al}_{0.48} \mathrm{In}_{0.52} \mathrm{As}$ cap and the one at $249 \mathrm{~cm}^{-1}$ originating in the superlattice. In strained layer superlattices, quantum confinement and strain effects both contribute to the optical phonon energies. In unstrained materials like GaAs/AlAs, the phonon energy levels correspond to those of bulk at the discrete wave vectors given by $k_{m}=m \pi /(n+1) a$, where $n$ is the number of monolayers of width $a$, and $1 \leqslant m \leqslant n$. The model of Cerdeira et $a l .{ }^{18}$ was used to estimate the strain shift of the LO phonons. Using the data in that reference for InAs, one calculates a (positive) frequency shift of approximately 13 $\mathrm{cm}^{-1}$ for the LO phonon at the lattice mismatch of 0.038 , appropriate for InAs $/ \mathrm{Al}_{0.48} \mathrm{In}_{0.52} \mathrm{As}$. The expected (negative) shift due to quantum confinement is about $6 \mathrm{~cm}^{-1}$, so that the observed shift of $8 \mathrm{~cm}^{-1}$ from the bulk InAs LO phonon energy is reasonable. For layers in tensile strain, the expected phonon energy shift is negative. If one assumes the elastic properties of AlAs and GaAs are similar, this value is expected to be about $15 \mathrm{~cm}^{-1}$, which, when added to the estimated quantum confinement shift of 12 $\mathrm{cm}^{-1}$, is close to the observed shift of $30 \mathrm{~cm}^{-1}$. The optical phonon energies of the monolayer sample are virtually identical to those of the alloy.

To provide additional confirmation of structure and periodicity, $x$-ray diffraction measurements were made on both samples. Figure 2 shows the diffracted beam intensity as a function of diffraction angle for the mono- and bilayer samples. In both cases the presence of $(h 00)$ peaks ( $h$ odd), which are forbidden in the random alloy, confirms the additional (super)periodicity. In contrast to previous $\mathrm{MBE}$ results for (InAs) ${ }_{2}(\mathrm{AlAs})_{2}$, the bilayer sample studied here clearly exhibits a higher order (900) diffraction peak, perhaps indicative of superior interface uniformity. ${ }^{12}$ For this sample the satellite peaks correspond to a 


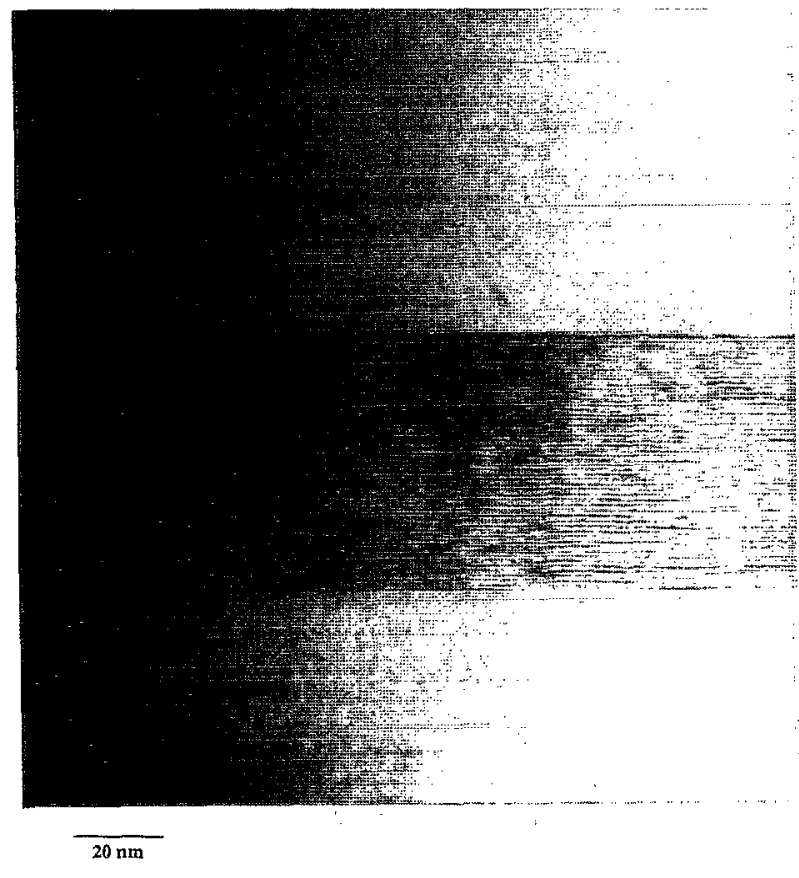

FIG. 3. High resolution cross sectional TEM image of bilayer.

superperiod of $11.89 \AA$, close to the calculated value of $11.74 \AA$. The splitting of the $(100)$ and $(300)$ peaks in the monolayer scan indicates the layer thickness is not equal to an integral number of monolayers. ${ }^{7}$ From the positions of these peaks we deduce that $n$, the number of monolayers actually present, is equal to $1.17 .^{7}$ The departure from the ordered structure is probably due to beam flux transients caused by opening and closing the source shutters.

Figure 3 is a high resolution cross sectional TEM image of the two monolayer sample, clearly showing the compositional modulation. In this photograph, InAs (AlAs) layers appear dark (light). Although some interface nonuniformity is suggested, good overall homogeneity is indicated.

In summary, we have grown short period strained layer $(\operatorname{InAs})_{1}(\mathrm{AlAs})_{1}$ and $(\mathrm{InAs})_{2}(\mathrm{AlAs})_{2}$ superlattices by MEE and investigated their structural properties using Raman scattering, $x$-ray diffraction, and TEM. For the bilayer sample all measurements revealed the existence of the intended superperiodicity as well as the presence of some random alloy or disorder. The splitting of the superlattice $x$-ray diffraction satellite peaks for the monolayer indicates interface broadening which we attribute to beam flux transients.

The authors wish to thank R. Jacowitz and Dr. S. Laderman of Hewlett-Packard Laboratories, Palo Alto, for the $\mathrm{x}$-ray data. J. Berry is acknowledged for expert technical assistance. This work was supported by the Joint Services Electronics Program (Contract No. F49620-90-C0039) and the Innovative Science and Technology Program (Contract No. N0014-89-J-1311).

${ }^{1}$ T. Yao, Jpn. J. Appl. Phys. 22, L680 (1983).

${ }^{2}$ J. Singh, S. Dudley, B. Davies, and K. K. Bajaj, J. Appl. Phys. 60, 3167 (1986).

${ }^{3}$ T. P. Pearsall, G. Beuchet, J. P. Hirtz, N. Visentin, and M. Bonnet, Institute of Physics Conf. Ser. No. 56, 639 (1980).

${ }^{4}$ K. Seo, P. K. Bhattacharya, and K. R. Gleason, Electron. I.tt. 23, 259 (1987).

${ }^{5}$ C. Peng, M. I. Aksun, A. A. Kelterson, H. Morkoc, and K. R. Gleason, IEEE Electron Device Lett. EDL-8, 24 (1987).

${ }^{6}$ T. Itoh, A. S. Brown, L. H. Camnitz, G. W. Wicks, J. D. Berry, and L. F. Eastman, Institufe of Physics Conf. Ser. No. 79, 571 (1986).

${ }^{7}$ T. Fukui and H. Saito, Jpn. J. Appl. Phys. 23, L521 (1984).

${ }^{8}$ M. Razeghi, P. Maurel, F. Omnes, and J. Nagle, Appl. Phys. Lett. 51, 2218 (1987).

${ }^{9}$ B. T. McDermott, N. A. El-Masry, M. A. Tischler, and S. M. Bedair, Appl. Phys. Lett. 51, 1830 (1987).

${ }^{10}$ J. M. Gérard, J. Y. Marzin, B. Jusserand, F. Glas, and J. Primot, Appl. Phys. Lett. 54, 30 (1989).

${ }^{11}$ K. Nishi, T. Anan, Y. Ide, and K. Onabe, J. Cryst. Growth 95, 202 (1989).

${ }^{12}$ Y. Horikoshi, M. Kawashima, and H. Yamaguchi, Jpn. J. Appl. Phys. 27, 169 (1987).

${ }^{13}$ J. W. Matthews and A. F. Blakeslee, J. Cryst. Growth 27, 118 (1974).

${ }^{14}$ F. Houzay, C. Guille, J. M. Moison, P. Henoc, and F. Barthe, J. Cryst. Growth 81, 67 (1987).

${ }^{15}$ C. Colvard, R. Merlin, M. V. Klein, and A. C. Gossard, Phys. Rev. Lett. 43, 298 (1980).

${ }^{16}$ B. Jusserand, D. Paquet, and A. Regreny, Phys. Rev. B 30, 6245 (1984).

${ }^{17}$ P. V. Santos, A. K. Sood, M. Cardona, and K. Ploog, Phys. Rev. B 37, $6381(1988)$.

${ }^{18}$ F. Cerdeira, C. J. Buchenauer, F. H. Pollak, and M. Cardona, Phys. Rev. B 5, 580 (1972). 